Cultural Cognition Project Working Paper No. 89

Preliminary draft-subject to revision

Address correspondence to dan.kahan@yale.edu

\title{
The Tragedy of the Risk-Perception Commons: Culture Conflict, Rationality Conflict, and Climate Change
}

\author{
Dan M. Kahan \\ Yale University \\ Ellen Peters \\ Ohio State University \\ Donald Braman \\ George Washington University
}

\author{
Maggie Wittlin \\ Cultural Cognition Project Lab \\ Paul Slovic \\ Decision Research \\ Lisa Larrimore Ouellette \\ Cultural Cognition Project Lab \\ Gregory Mandel \\ Temple University
}

Authors' Note. Research for this paper was funded by the National Science Foundation, Grant SES 0922714. Correspondence concerning this article should be addressed to Dan M. Kahan, Yale Law School, PO Box 208215, New Haven, CT 06520. Email: dan.kahan@yale.edu. 


\begin{abstract}
The conventional explanation for controversy over climate change emphasizes impediments to public understanding: limited popular knowledge of science, the inability of ordinary citizens to assess technical information, and the resulting widespread use of unreliable cognitive heuristics to assess risk. A large survey of U.S. adults $(N=1540)$ found little support for this account. On the whole, the most scientifically literate and numerate subjects were slightly less likely, not more, to see climate change as a serious threat than the least scientifically literate and numerate ones. More importantly, greater scientific literacy and numeracy were associated with greater cultural polarization: respondents predisposed by their values to dismiss climate change evidence became more dismissive, and those predisposed by their values to credit such evidence more concerned, as science literacy and numeracy increased. We suggest that this evidence reflects a conflict between two levels of rationality: the individual level, which is characterized by the citizens' effective use of their knowledge and reasoning capacities to form risk perceptions that express their cultural commitments; and the collective level, which is characterized by citizens' failure to converge on the best available scientific evidence on how to promote their common welfare. Dispelling this "tragedy of the risk-perception commons," we argue, should be understood as the central aim of the science of science communication.
\end{abstract}




\section{Introduction: Is public opinion rational?}

Controversy over climate change is commonly attributed to a deficit in public comprehension of scientific information. The most straightforward explanation is ignorance: the public knows too little science to understand the evidence or to avoid being misled by distortions of it. A subtler account puts the blame on widespread cognitive biases and related limitations on the capacity of citizens to assess information about risk. In short, because members of the public do not know what scientists know, or think the way scientists think, they predictably fail to take climate change as seriously as perfectly rational riskevaluators would.

The goal of this paper is to challenge this critique of the rationality of public opinion on climate change. Our motivation is in part to show how poorly supported the conventional picture of public dissensus is by empirical evidence: scientific examination does not bear out the premise that deficiencies in science education or defects in individual reasoning explain conflict over climate change.

But an even more fundamental objective is to advance a more precise diagnosis of the kind of irrationality that afflicts public deliberations on climate change. "Irrationality" describes a state of antagonism between an agent's goals and the decision-making capacities that the agent uses to attain them. Accordingly, it is necessary to specify who the agent is and what good he or she or it is trying to attain; only then can one identify and assess the performance of the reasoning processes being employed (Gigenrenzer 2000). The dominant critique of public rationality, we submit, doesn't pay sufficient attention to these issues.

After presenting our data, we will suggest that the rationality question should be asked and answered at two different levels (McMahon 2001). The first is individual. For reasons that make sense from a variety of psychological perspectives, individuals behave as if they were trying to maximize correspondence between their own perceptions of societal risks and the perceptions that predominate within the cultural groups to which they belong (Sherman \& Cohen 2006; Kahan, Braman, Gastil, Slovic \& Mertz 2007). Individuals need to use a variety of cognitive faculties to attain this correspondence. Judged within 
this framework, the evidence suggests that individuals are displaying an impressively high degree of rationality in the formation of their beliefs about climate change.

Nevertheless, public opinion can be understood to be irrational at the collective level. This perspective sees society as the agent and maximization of the welfare of its members as the goal. What makes collective decision-making irrational, moreover, has nothing to do with limited scientific literacy or widespread cognitive biases; on the contrary, the source of the problem is just how exceedingly rational society's members are at the individual level: The reliable capacity of individuals to conform their personal beliefs to those that predominate within their respective cultural groups prevents those groups from converging on beliefs that make all of their members materially better off.

This conflict between individual and collective rationality is not inevitable. It occurs only because of contingent, mutable, and fortunately rare conditions that make one set of beliefs about risk congenial to one cultural group and an opposing set congenial to another. Neutralize these conditions, we will argue, and the conflict between the individual and collective levels of rationality is resolved. Perfecting our knowledge of how to achieve this state should be a primary aim of the science of science communication.

\section{The public irrationality thesis}

To sharpen the focus, we begin with a more detailed sketch of the account we mean to challenge. That account fuses three explanations for public dissensus over climate change.

The first explanation can be called the "scientific illiteracy" theory. According to this view, skepticism about climate change can be traced to poor public comprehension of science. Lacking a solid foundation in the basics of science and the scientific method, a substantial proportion of the public cannot understand evidence of the reality, the causes, and the unfolding consequences of climate change and is readily deceived by misrepresentations relating to that evidence (e.g., Hartley, Wilke, Scharamm, D’Avanzo \& Anderson 2011; Pidgeon \& Fischhoff 2011; Ungar 2000).

The second explanation can be called the "bounded rationality" theory. This position lays emphasis on a model of cognition associated with recent work in cognitive psychology and behavioral econom- 
ics. The model posits two discrete forms of information-processing: "System 1," which consists in rapid visceral judgments that manifest themselves in a collection of decision-making "heuristics"; and "System 2," which involves conscious reflection and calculation - modes of reasoning that are slower but more accurate than the heuristical ones associated with System 1 (Kahneman 2003). Most members of the public, according to the bounded rationality theory, employ System 1 reasoning most of the time. Although System 1 works well for most of the contingencies in daily life, citizens' predominant reliance on heuristic rather than more analytic modes of reasoning leads them to underestimate climate change risks, which are remote and abstract compared to a host of emotionally charged risks such as those associated with nuclear power or terrorism that the public in fact tends to overestimate (Weber 2006; Sunstein 2007).

The third explanation is the "cultural cognition" theory. Drawing on concepts and methods from psychology, anthropology, and communication, this theory holds that individuals can be expected to form perceptions of risk that reflect and reinforce values that they share with others (Douglas \& Wildavsky 1982). Public dissensus over climate change, according to this view, originates in a more basic conflict between opposing groups whose members' cultural outlooks dispose them to form opposing perceptions of environmental and technological risks generally (Kahan 2010; Verwij, Douglas, Ellis, Engle, Hendriks, Lohmann, Ney, Rayner \& Thompson 2006).

The conventional understanding of public opinion on climate change synthesizes these three explanations. In this account, a substantial fraction of the population is seen as lacking both the basic knowledge and the psychological capacity necessary to reliably interpret scientific evidence. As a result, they must rely on heuristic substitutes, which systematically bias their estimations of climate change risks. Cultural cognition - the conforming of beliefs to those that predominate within one's group — is simply one of these heuristics (Sunstein 2006). The result is the failure of the public — or at least a large proportion of it— to form the views of climate change risk held among more knowledgeable, dispassionate experts (Weber \& Stern 2011).

We will call this position the "public irrationality thesis" or "PIT." Our claim is that PIT is contrary to empirical evidence of who believes what about climate change. 


\section{Study results}

The evidence we will rely on comes from a survey of a large, nationally representative sample of U.S. adults. The survey measured respondents' values using scales-Hierarchy-Egalitarianism (“Hierarchy") and Individualism-Communitarianism ("Individualism") — associated with studies of the socalled cultural theory of risk (Douglas \& Wildavsky 1982). It also measured the respondents' "science literacy." For that purpose, we used a set of questions from the National Science Foundation (National Science Board 2010) "Science and Engineering Indicators" (e.g., "It is the father's gene that decides whether the baby is a boy or a girl—true or false?"; "Antibiotics kill viruses as well as bacteria—true or false?"), which have been widely used over an extended period to test familiarity with basic science (Allum, Sturgis, Tabourazi \& Brunton-Smith 2008).

We also measured the survey respondents' "numeracy"- that is, their capacity to comprehend and use quantitative information as measured by responses to mathematical word problems (e.g., "If Person A's chance of getting a disease is 1 in 100 in ten years, and person B's risk is double that of A, what is B's risk?"; "A bat and a ball cost $\$ 1.10$ in total. The bat costs $\$ 1.00$ more than the ball. How much does the ball cost?"). High numeracy depends on System 2 reasoning. As a result, individuals' numeracy scores can be viewed as a measure of their capacity and disposition to use System 2 rather than System 1 in making assessments of risks and related matters (Reyna, Nelson, Han \& Dieckman 2009; Peters, Västfjäll, Slovic, Mertz, Mazzocco \& Dickert 2006).

Finally, we measured our respondents' perceptions of the risk of climate change. On a scale of 0 ("no risk") to 10 ("extreme risk"), the average rating was $5.7(S D=3.4)$. That number in itself, we submit, is not very informative. However, the point of soliciting responses on the 0-10 scale was to enable assessments of variance in respondents' ratings. By identifying what sorts of characteristics are associated with more concern and what ones with less, we can test various hypotheses about why the average mem- 
ber of the public fails to take the risk of climate change as seriously as expert scientists believe he or she should.

The scientific illiteracy and bounded-rationality theories both support straightforward, testable predictions. The science illiteracy theory posits that the average person underestimates the seriousness of climate change because he or she is not sufficiently knowledgeable about science. If that explanation is true, concern over climate change should be positively correlated with science literacy-that is, it should increase as people become more science literate. Similarly, the "bounded rationality" theory predicts that as people become more numerate they should also become more concerned with climate change: more numerate people are more likely to use systematic as opposed heuristic reasoning and hence should form a perception of climate change risk that is less biased toward underestimation.

\section{"How much risk do you believe climate change poses to human health, safety, or} prosperity?"
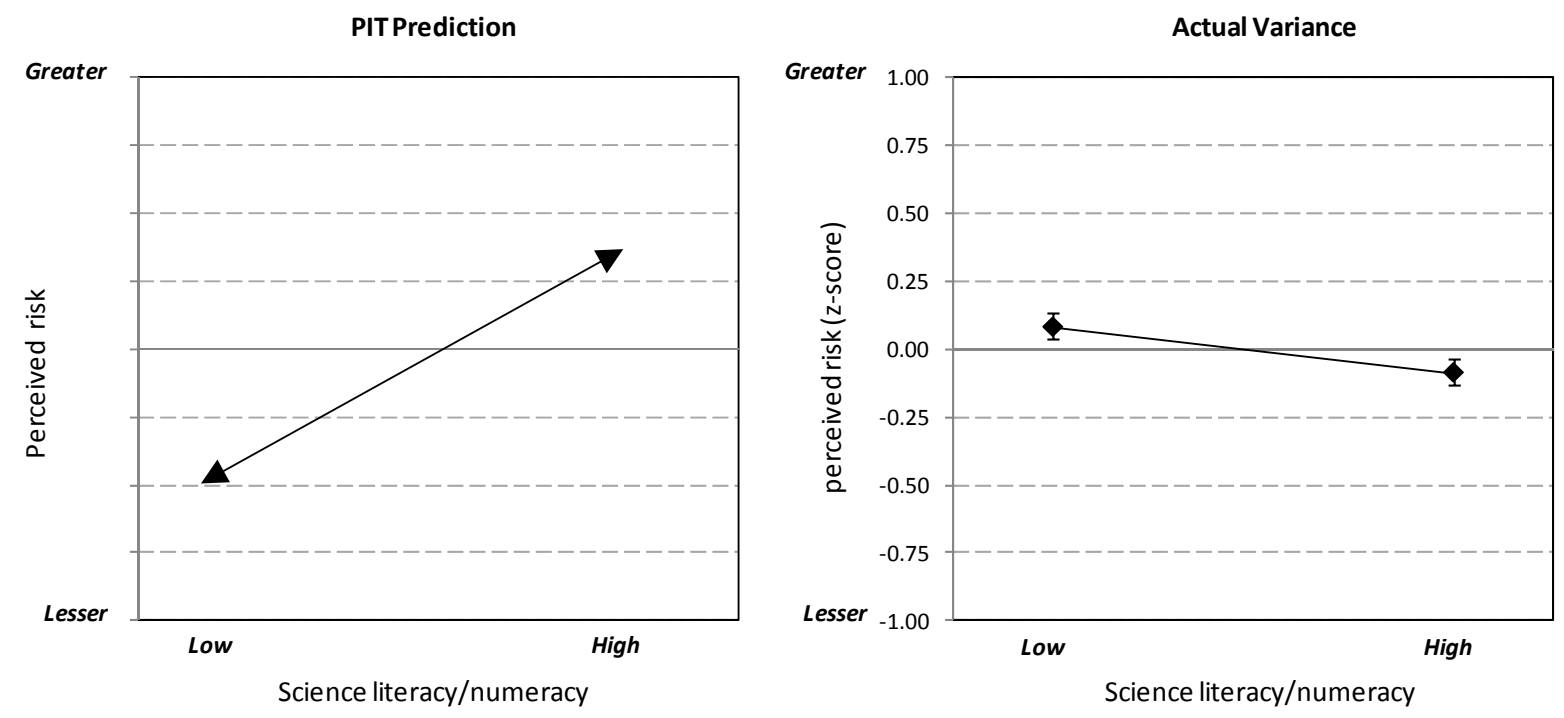

Figure 1. PIT prediction vs. actual impact of science literacy and numeracy on climate-change risk perceptions. $N=1540$. Derived from univariate regression (SI Table 3, Model 1). Contrary to PIT predictions, higher degrees of science literacy and numeracy are both associated with small decreases in the perceived seriousness of climate-change risks.. "Low" and "High" reflect values set at $-1 S D$ and $+1 S D$ on Science/Numeracy, a composite scale based on respondents' science literacy and numeracy scores. Responses on $0-10$ risk scale $(M=5.7, S D=3.4)$ converted to z-score to promote ease of interpretation. CIs reflect 0.95 level of confidence.

Both of these predictions were unsupported. As respondents' science literacy scores increased, their concern with climate change decreased $(r=-0.05, p=0.05)$. The difference is small—but neverthe- 
less inconsistent with the science-illiteracy theory prediction that those who scored higher in science literacy would be significantly more concerned. There was also a small negative correlation between numeracy and climate-change risk $(r=-0.09, p<0.01)$ - a result inconsistent with the "bounded rationality" theory prediction. The impact of increased science literacy and numeracy on climate change risk perceptions is illustrated in Figure 1,which plots the impact of increases in "Science/Numeracy," a combined index of science literacy and numeracy $(\alpha=0.85)$.

The cultural cognition theory also generates a testable prediction. This theory posits that persons who subscribe to a "hierarchical, individualistic" worldview—one that simultaneously ties authority to conspicuous social rankings and eschews collective interference with the decisions made by individuals possessed of such authority — can be expected to be skeptical of claims of environmental and technological risks. Such people, according to the theory, intuitively perceive that widespread acceptance of such claims would license restrictions on commerce and industry, forms of behavior that Hierarchical Individualists value. In contrast, persons who hold an "egalitarian, communitarian" worldview—one that favors less regimented forms of social organization and greater collective attention to securing individual needs - tend to be morally suspicious of commerce and industry, which they see as the source of unjust disparities in wealth and power. They therefore find it congenial, the theory posits, to see those forms of behavior as dangerous and thus worthy of restriction. On this view, then, we should expect Egalitarian Communitarians to be more concerned than Hierarchical Individualists with climate change risks (Douglas \& Wildavsky 1982).

Consistent with previous studies (Kahan, Braman, Gastil, Slovic \& Mertz 2007; Leiserowitz 2006), the data we collected support this prediction (Figure 2). Hierarchical Individualists (subjects who scored in the top half of both the Hierarchy-Egalitarian and Individualist-Communitarian cultural worldview scales) rated climate change risks significantly lower $(M=3.15, S E M=0.17)$ than did Egalitarian Communitarians (respondents whose scores placed them in the bottom half of the two cultural worldview scales $)(M=7.4, S E M=0.13)$. 
It is thus plain that differences in our respondents' cultural values had a bigger effect on perception of climate-change risks than did differences in their degrees of either science literacy or numeracy. The correlations between Science/Numeracy, on the one hand, and Hierarchy $(r=0.15, p<0.01)$ and Individualism $(r=-0.04, p=0.09)$ were weak (see Supplementary Information). Multivariate analysis confirmed that the impact that cultural orientations exert on risk perceptions does not recede when science literacy and numeracy are controlled for (SI Table 3, Models 2-3 \& SI Figure 6).
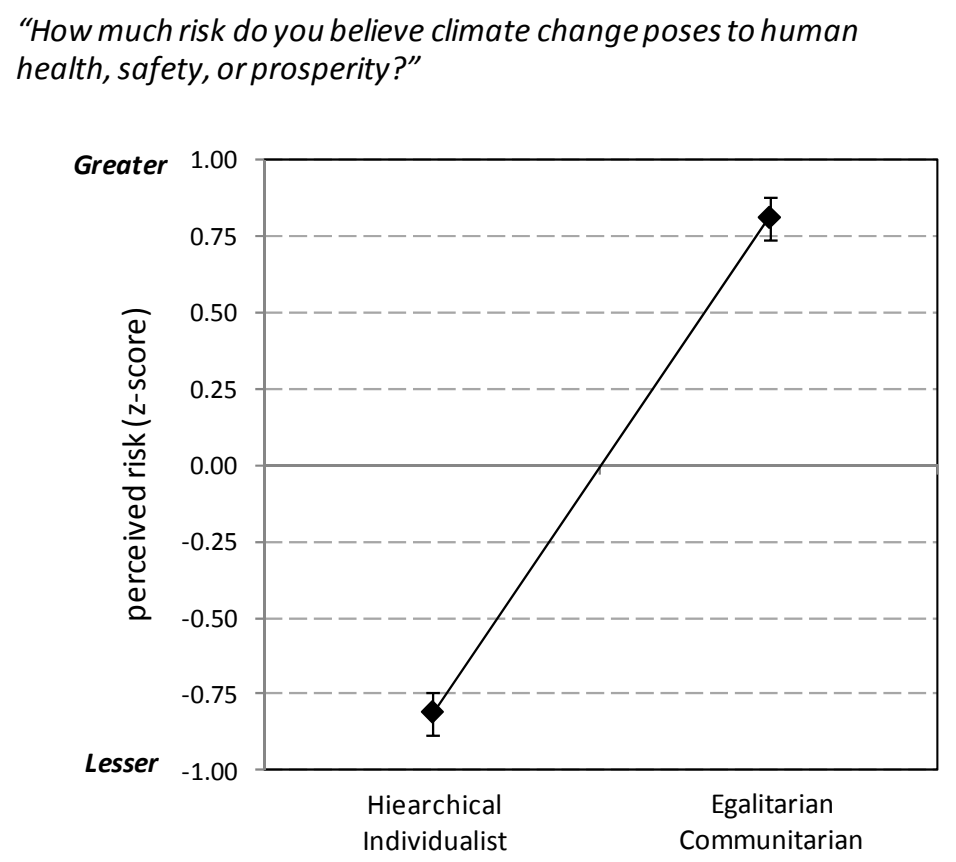

Figure 2. Cultural variance in climate-change risk perceptions. Derived from multivariate regression (SI Table 3 , model 2). $N=1540$. Estimated risk scores control for science literacy (set to its mean value). "Hierarchical individualist" and "Egalitarian communitarian" reflect values set, respectively, at $+1 S D$ and $-1 S D$ on both the Hierarchy and Individualism cultural worldview scale predictors. Responses on 0 -10 risk scale $(M=5.7, S D=3.4)$ converted to z-score to promote ease of interpretation. CIs reflect 0.95 level of confidence.

These findings, however, certainly do not rule out treating public assessment of climate change risks as unreasoned. Under PIT, for example, science literacy, numeracy, and cultural cognition are viewed as reinforcing one another: People who understand science and who engage in the System 2 reasoning style characteristic of scientists are expected to converge on the best available scientific evidence of climate change (and other) risks; people who lack such understanding and who lack such powers of reason must rely on their "gut" - that is, on less reliable System 1 heuristics, including cultural cognition. 
PIT thus predicts that as science literacy and numeracy increase, the skepticism over climate change associated with a hierarchical, individualistic worldview should lessen and the gap between people with hierarchical individualistic worldviews and those with egalitarian communitarian ones should diminish (Figure 3).

"How much risk do you believe climate change poses to human health, safety, or prosperity?"
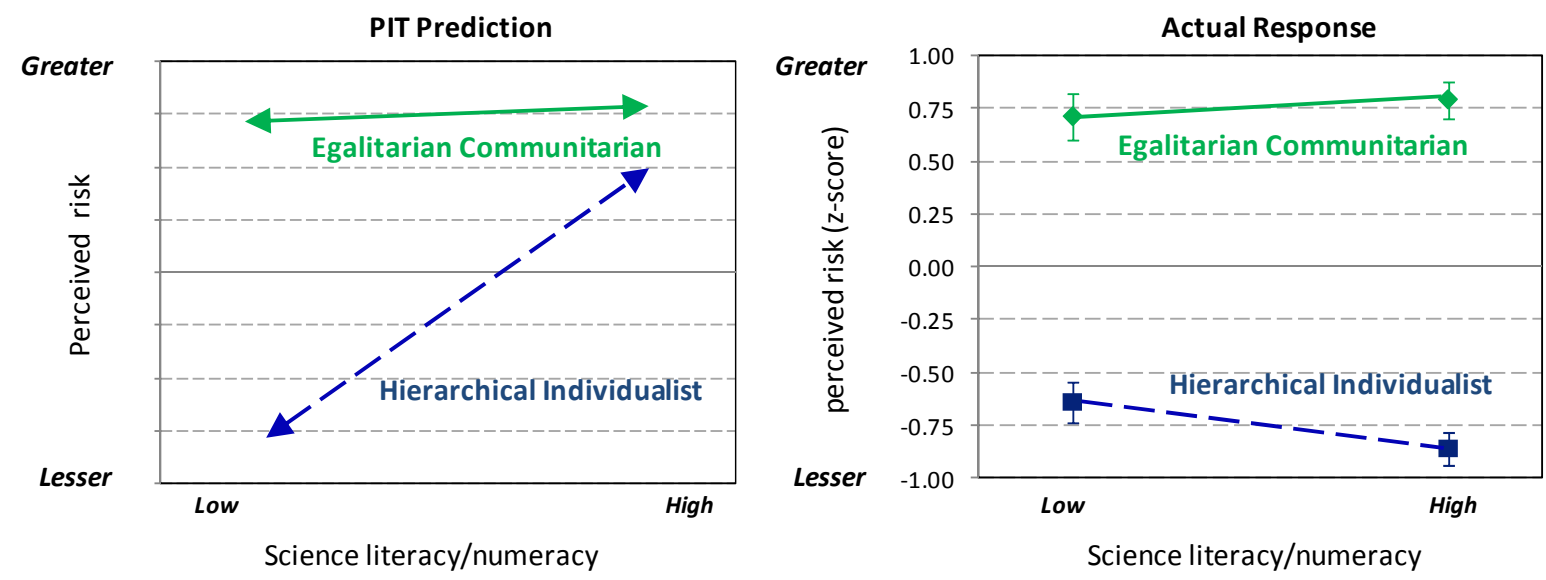

Figure 3. PIT prediction vs. actual impact of interaction between science literacy and numeracy, on the one hand, and cultural worldviews, on the other. $N=1540$. Derived from multivariate regression SI Table 3 , model $3)$. Contrary to PIT's predictions, highly science literate and numerate Hierarchical Individualists are more skeptical, not less, of climate-change risks. "Hierarchical Individualist" and "Egalitarian Communitarian" reflect values set, respectively, at $+1 S D$ and $-1 S D$ on both the Hierarchy and Individualism cultural worldview scale predictors. "Low" and "high" reflect values set at $-1 S D$ and $+1 S D$ on Science/Numeracy scale, a composite scale based on respondents' science literacy and numeracy scores. Responses on 0 -10 risk scale $(M=5.7, S D=3.4)$ converted to zscore to promote ease of interpretation. CIs reflect 0.95 level of confidence.

But this prediction, too, was unsupported by the data. Among Egalitarian Communitarians, science literacy and numeracy, as reflected in Science/Numeracy, showed a modest positive correlation with concern about climate-change risks $(r=0.08, p=0.03)$. But among Hierarchical Individualists, Science/Numeracy is negatively correlated with such concern $(r=-0.12, p=0.03)$. Hence, cultural polarization actually gets bigger, not smaller, as science literacy and numeracy increase (Figure $3 \&$ SI Figure 7).

We also examined our survey respondents' perceptions of nuclear power risks, the seriousness of which they ranked on the same 0 ("no risk at all") to 10 ("extreme risk") scale $(M=6.1, S D=3.0)$. Here, both science literacy $(r=-0.41, p<0.01)$ and numeracy $(r=-0.25, p<0.01)$ were associated with dimi- 
nished risk concern (Figure $4 \&$ SI Figure 6). This result is arguably consistent with PIT. Historically, members of the public have been understood to be more concerned about nuclear power than they should be based on the best available scientific evidence. If, consistent with PIT, we attribute the public's view to deficits in reason, then we should expect to see concern with nuclear power risks abate as science literacy and numeracy increases.

What PIT doesn't predict is the interaction observed between numeracy and science literacy, on the one hand, and cultural values, on the other. The impact of science literacy and numeracy in reducing concern with nuclear power is significantly greater in Hierarchical Individualists. As a result, the gap between Hierarchical Individualists and Egalitarian Communitarians again expands as numeracy and science literacy increase. Because the contribution that culture makes to public disagreement grows in strength as science literacy and numeracy increase, it is not plausible to see the impact of cultural cognition as a heuristic substitute for scientific knowledge and System 1 reasoning capacity (Figure 4 \& SI Figure 7).

In a previous study, it was found that Hierarchical Individualists and Egalitarian Communitarians were equally likely to hold mistaken beliefs about "scientific consensus" (as reflected in National Academy of Sciences "expert consensus" reports) on culturally charged risk issues such as nuclear power, climate change, and gun control (Kahan, Jenkins-Smith \& Braman 2011). An experimental component of the same study found that individuals tended to recognize scientists (ones identified as members of the National Academy of Sciences) as "experts" on these issues conditional on the fit between the positions attributed to the putative expert and the subjects' own cultural predispositions on those issues.

The data in this study suggest that the impact of cultural cognition on perceptions of scientific evidence only grows in strength as individuals become more knowledgeable about science and develop greater facility with technical reasoning. Egalitarian Communitarians possessed of high science literacy and numeracy were most likely to diverge from the mean subject's presumed underestimation of climate change risks. Yet on nuclear power risks, those same respondents shared the mean subject's presumed overestimation of the dangers of nuclear power. Likewise, Hierarchical Individualists who displayed high 
science literacy and numeracy were the least likely to see nuclear power as unsafe but the also the most skeptical of climate change.

"How much risk do you believe nuclear power poses to human health, safety, or prosperity?"
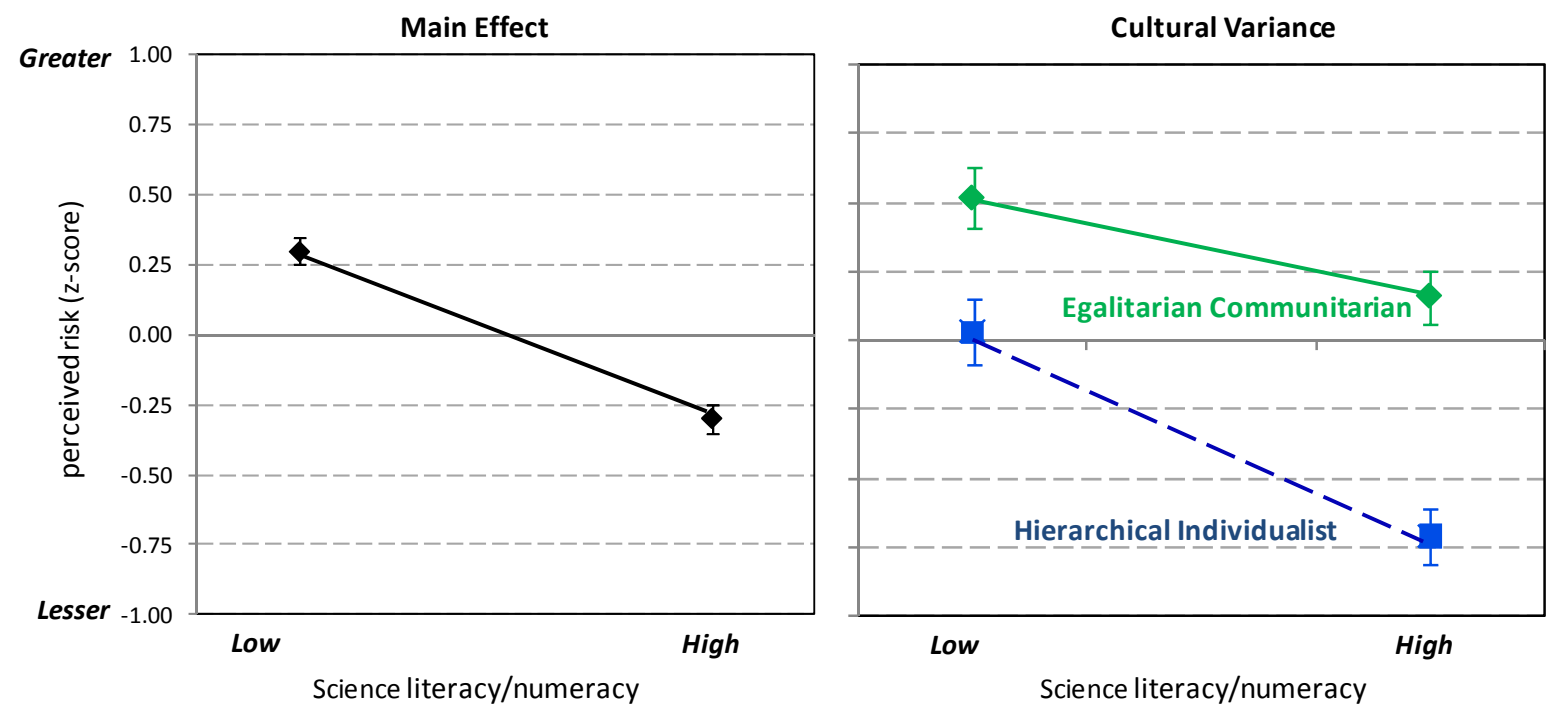

Figure 4. Impact of science literacy and numeracy, and of interaction between science literacy and numeracy, on the one hand, and cultural worldviews, on the other, in prediction of nuclear-power risk perceptions. $N=$ 1540. "Main Effect" derived from univariate regression (SI Table 4, Model 3). The perceived risk of nuclear power is lower among the most science-literate and most numerate respondents than among the least science-literate and numerate ones. However, again contrary to PIT, cultural polarization does not diminish but instead increases as respondents become more science literate and numerate. "Hierarchical individualist" and "Egalitarian communitarian" reflect values set, respectively, at $+1 S D$ and $-1 S D$ on both the Hierarchy and Individualism cultural worldview scale predictors. "Low" and "high" reflect values set at $-1 S D$ and $+1 S D$ on Science/Numeracy scale, a composite scale based on respondents' science literacy and numeracy scores. Responses on 0 -10 risk scale $(M=6.1, S D=3.0)$ converted to z-score to promote ease of interpretation. CIs reflect 0.95 level of confidence.

\section{Rationality-individual vs. collective}

The evidence we have presented is at odds with PIT — the "public irrationality thesis." PIT implies that members of the public are divided about climate change science because they have limited scientific knowledge and limited capacity to reason about evidence in a scientific manner. Our data, however, show that as individuals become more science literate and more proficient in the mode of reasoning featured in scientific inquiry, they don't reliably form beliefs more in line with scientific consensus. Instead, they form beliefs that are even more reliably correlated with those of the particular cultural group to which they belong. 
It doesn't follow, however, that public opinion on climate change is "rational." We submit that the evidence we've presented (consistent with research on the cultural theory of risk generally) suggests that evaluating the rationality of public opinion is a more complex exercise than PIT envisions. In fact, we believe the question of whether the public's beliefs about climate change are "rational" must be asked on (at least) two distinctive levels, and yields different answers at each.

a. Individual expressive rationality. The first level is individual. Are individuals forming beliefs and otherwise processing information about climate change in a manner conducive to the advance of their personal aims and goals?

Among the aims of all members of the public (we'll unheroically assume) are health, safety, and access to the material resources necessary for sustenance and comfort. The myriad risks associated with climate change (from failing to take steps necessary to avert environmental catastrophe to adopting costly but ineffectual or unnecessary environmental regulations) threaten those ends.

That does not mean, however, that the ordinary member of the public will be harmed if she herself ignores or misinterprets scientific data relating to climate change. Her well-being will likely depend critically on whether her society, and others around the globe, implement policies consistent with the best available scientific evidence. But it would be peculiar for her to conclude that the likelihood that any society will adopt such policies will be affected by her own formation of correct beliefs. Nor is it plausible for the typical member of the public to imagine that anything she, as an individual, does - as a producer of carbon emissions, say, or as a voter in democratic elections - will by itself aggravate or reduce the dangers that climate change might pose. She is just not consequential enough one way or the other to matter (Downs 1957). Indeed, if the typical member of the public concluded that the scientific accuracy of her own perception of climate change risks was either a necessary or a sufficient condition for abatement of those risks, that belief would itself be evidence of irrationality (Benn 1978).

At the same time, the beliefs that the typical member of the public forms about climate change will likely have an impact on how she gets along with people she interacts with in her daily life. A Hierarchical Individualist in Oklahoma City who proclaims that he thinks that climate change is a serious and 
real risk might well be shunned by his coworkers at a local oil refinery; the same might be true for an Egalitarian Communitarian English professor in New York City who reveals to colleagues that she thinks that "scientific consensus" on climate change is a "hoax." They can both misrepresent their positions, of course, but only at the cost of having to endure the anxiety of living a lie, not to mention the risk that they'll slip up and reveal their true convictions. Given how much they depend on others for supportmaterial and emotional - and how little impact their beliefs have on what society does to protect the physical environment, they are better off when they form perceptions of climate change risk that minimize this danger of community estrangement.

In such circumstances, that is exactly what is likely to happen. A long-standing body of work in social psychology suggests that individuals are motivated to fit their beliefs to those of people with whom they are intimately connected (Sherman \& Cohen 2002; Chen, Duckworth \& Chaiken 1999; Kunda 1990). Both to avoid dissonance and to secure their standing within such groups, they predictably seek out and credit information supportive of "[s]elf-defining ... values [and] attitudes" (Giner-Sorolla \& Chaiken 1997, p. 85), among them the shared worldviews featured in the study of cultural cognition of risk (Kahan, Braman, Gastil, Slovic \& Mertz 2007).

Individuals can be said to be displaying expressive rationality (Anderson 1993) when they reliably make use of the cognitive capacities necessary to interpret and communicate identity-defining beliefs. Decoding the cultural significance of contested empirical claims relating to climate change, nuclear waste disposal, gun control, and other such issues is hardly straightforward. It demands careful attention to various cues, including the distribution of beliefs on these matters across different groups (Cohen 2003), the emotional resonances of various types of arguments (Druckman \& Bolsen in press; Kahan, Braman, Slovic, Gastil \& Cohen 2009), and the cultural identities of the people presenting them (Cohen 2003; Kahan, Braman, Cohen, Gastil \& Slovic 2010). Forming beliefs that convey their affinity to those with whom they share cultural attachments demands appropriate calibration and unconscious activation of emotional sensibilities that motivate individuals to seek out and assent to evidence supportive of their groups' positions (Sherman \& Cohen 2006). The predictive power of cultural worldviews implies that the 
average member of the public displays a high degree of expressive rationality when deploying these faculties (Gigerenzer 2000).

The motivation to fit information to identity-defining beliefs shapes all manner of cognitionincluding the types associated with both System 1 and System 2 reasoning (Chen, Duckworth \& Chaiken 1999; Giner-Sorolla \& Chaiken 1997). It should therefore come as no surprise that the highest degrees of expressive rationality are found in members of the public with the highest degrees of science literacy and numeracy. As ordinary members of the public learn more about science and develop a greater facility with numerical information, they become more skillful in seeking out and making sense of - or if necessary explaining away_empirical evidence relating to their groups' positions on climate change and other issues. Their reward is even greater convergence between what they believe about how the world works and what they desire to be true.

b. Collective welfare irrationality. Assessing whether any cognitive process is "rational" requires identifying who the agent is and what he or she is (or should be) trying to maximize. Even when the contribution cultural cognition makes to expressive rationality promotes individuals' interests without compromising any other individual end, the common exercise of this form of reasoning can be manifestly irrational from the point of view of a self-governing society (McMahon 2001).

We assume (again, unheroically) that a self-governing society is more likely to secure its members health, safety, and prosperity when it adopts policies informed by the best available scientific information. This state of affairs is most likely to occur when such a society's citizens uniformly and rapidly converge in their recognition of the best available scientific evidence reveals about risk and risk abatement. Cognitive dynamics that systematically impede such convergence are, from the point of view of such a society, a form of irrationality.

As reliably as it promotes expressive rationality at the individual level, cultural cognition will often be collectively irrational from this welfarist perspective. What makes it expressively rational for individuals to adopt particular beliefs about risk is not the truth of those beliefs but rather the congruence between those beliefs and individuals' cultural commitments. As a result, if beliefs about a societal risk such 
as climate change come to bear meanings congenial to some cultural outlooks but hostile to others, expressively rational individuals will fail to converge on the best available scientific information (or at least fail to converge as rapidly as they otherwise would). Indeed, individuals of opposing cultural outlooks who are the most scientifically literate and most numerate will be the ones least likely to see things eye to eye-and will likely pull those who understandably look to them for guidance on complex matters into states of intense disagreement as well. Thus, while it is, for all intents and purposes, costless for any individual to form a perception of risk that is wrong but culturally congenial, it is not costless for societyindeed, it is very harmful to its collective welfare - for individuals in aggregate to form beliefs this way.

The conflict between expressive individual rationality and collective welfare rationality presents a classic collective action problem (Olson 1965; Lessig 1995). Every individual benefits (in a welfare sense) when democratic policymaking reflects the best available science relating to risk and risk abatement. But what any particular individual happens to believe about such matters doesn't make it any more — or less_-likely that democratically responsive policymakers will adopt such policies; for that reason, it is much more sensible for him or her to form beliefs solely on the basis of whether those beliefs are culturally congenial. Yet when all individuals respond, rationally, to this set of incentives, they predictably compromise their collective interest in living in a society whose democratically responsive policymakers avail themselves of the best available scientific information to promote their citizens' welfare.

\section{Conclusion: The science of science communication as a public good}

Our study results belie the conventional view that controversy over policy-relevant science is rooted in the public's lack of scientific knowledge and its inability to engage in technical reasoning. As ordinary people learn more science and become more proficient in modes of reasoning characteristic of scientific inquiry, they do not reliably converge on assessments of climate change risks supported by scientific evidence. Instead they more form beliefs that are even more reliably characteristic of persons who hold their particular cultural worldviews. Indeed, far from a symptom of how poorly equipped ordinary individuals are to reach rational conclusions on the basis of complex scientific data, disputes over 
issues like climate change, we've argued, are evidence of how remarkably well equipped they are to discern what stances toward such information satisfy their expressive interests. The high degree of rationality individuals display in forming risk perceptions that express their cultural values can itself inhibit collective welfare rationality by blocking citizens from converging on the best available scientific evidence on how to secure their common interests in health, safety, and prosperity.

Resolving controversies over climate change and like risk issues requires dispelling this tragedy of the risk-perception commons (Hardin 1968). A strategy that focuses only on improving transmission of sound scientific information, it should be clear, is highly unlikely to achieve this objective. The principal reason people disagree about climate change science is not that it has been communicated to them in forms they cannot understand. Rather, it is that positions on climate change convey values-communal concern versus individual self-reliance; prudent self-abnegation versus the heroic pursuit of reward; humility versus ingenuity; harmony with nature versus mastery over it — that divide them along cultural lines. Merely amplifying or improving the clarity of information on climate change science won't generate public consensus if risk communicators fail to take heed of the cues that determine what climatechange risk perceptions express about the cultural commitments of those who form them.

In fact, such inattention can deepen polarization. Citizens who hold hierarchical and individualistic values discount scientific information about climate change in part because they associate the issue with antagonism to commerce and industry. That association is aggravated when a communication identifies carbon-emission limits as the exclusive policy remedy for climate change (Kahan in press). Individuals are prone to interpret challenges to beliefs that predominate with their cultural community as assaults on the competence of those whom they trust and look to for guidance (Kahan, Braman, Cohen, Gastil \& Slovic 2010). That implication — which naturally provokes resistance—is likely to be strengthened when communicators with a recognizable cultural identity stridently accuse those who disagree with them of lacking intelligence or integrity. 
Public controversy over climate change science cannot be pinned entirely on mistakes in science communication. But it would be a mistake not to recognize that communicators' disregard of citizens' cultural outlooks has made things worse.

It would also be a mistake, at this point, for information communicators not to take care to avoid accentuating the cues that sustain cultural factionalization. It isn't the case, of course, that carbonemission controls are the only policy response to climate change risks; technologies that furnish a substitute for and that offset the effects of greenhouse-gas-producing energy sources can contribute, too. Many of these alternatives, such as nuclear power and geo-engineering, are likely to convey cultural resonances that affirm rather than threaten hierarchical and individualist confidence in the power of human ingenuity to overcome environmental constraints on economic production. There are also many hierarchical and individualistic people who believe in the need to take action, of one form or another, to address climate change risks, and who can be counted on to make the case for doing so in terms that appeal to rather than alienate members of the public who share their outlooks (Kahan 2010). The cultural richness of the full range of potential policy responses and available advocates are narrative resources for opening minds (Jones \& McBeth 2010; Verwij et al. 2006). It would be irrational for actors committed to disseminating sound scientific information not to make use of them.

Finally, it would be a mistake not to learn lessons from the misadventures that have beset efforts to communicate the science of climate change. Scientists are among the most trusted groups in the United States, which is a singularly pro-science society (Pew Research Center 2009). Bitter public disputes over science are in fact the exception rather than the rule. But those exceptions can be very damaging, to both the physical environment and the deliberative environment. Experience with the issue of climate change has shown that; but it has also furnished us data from which the science of science communication has derived important insights.

Citizens are most likely to be driven off the path of convergence on the best available science, this research shows, when issues of environmental and technological risk become freighted with cultural meanings that motivate diverse groups to form opposing positions. This state is by no means inevitable 
with respect to any particular issue. What's more, how such a state comes about does not defy empirical explanation, which can in turn be used to predict such controversies and to formulate strategies aimed at forestalling their occurrence or ameliorating their consequences should they occur.

Development of these forecasting and management tools is the task of the science of science communication. Establishing the institutions and procedures necessary for promoting their reliable use in policymaking is a public good of singular importance to the wellbeing of modern, culturally pluralistic democracies (Nisbet \& Mooney 2007). 


\section{Supplementary Information}

\section{Information on sample}

Study subjects consisted of a nationally representative general population sample of 1,540 Americans who were recruited by Knowledge Networks and who participated in study experiments via Knowledge Network's on-line testing facilities. Knowledge Networks (http://www.knowledgenetworks.com/) is a public opinion research firm with offices located throughout the United States. It maintains an active respondent pool of some 40,000 persons who are recruited to participate in online surveys and experiments administered on behalf of academic and governmental researchers and private businesses. Its recruitment and sampling methods assure a diverse sample that is demographically representative of the U.S. population (http://www.knowledgenet works.com/ganp/reviewer-info.html). Studies using Knowledge Networks facilities are routinely published in peer-reviewed academic journals (e.g., Miller, Scott \& Okamoto 2006; Harris, Maurer \& Kellermann 2010; Fischhoff, Gonzalez, Small \& Lerner 2003; see generally http://www.knowledgenetworks.com/ganp/docs/KN-Bibliography.pdf). The sample was 52\%

female, $76 \%$ white, and $8 \%$ African-American. The average age was 47 years. Forty-eight percent of the sample had an annunal household income under $\$ 50,000$. The median educational level was "some college."

\section{Measures}

a. Cultural worldviews. Subjects" cultural values or "worldviews" were measured with items used in previous studies of cultural cognition (Kahan, Braman, Cohen, Gastil \& Slovic 2010; Kahan, Braman, Slovic, Gastil \& Cohen 2009). These items characterize worldviews along two cross-cutting dimensions: Hierarchy-egalitarianism ("Hierarchy”) and Individualism-communitarianism ("Individualism"). The former set of items indicate attitudes toward social orderings that connect authority to stratified social 
roles based on highly conspicuous and largely fixed characteristics such as gender, race, and class (e.g., "Society as a whole has become too soft and feminine"; "We need to dramatically reduce inequalities between the rich and the poor, whites and people of color, and men and women"). The latter indicate attitudes toward social orderings that expect individuals to secure their own well-being without assistance or interference from society versus those that assign society the obligation to secure collective welfare and the power to override competing individual interests (e.g., "The government interferes far too much in our everyday lives"; "The government should do more to advance society's goals, even if that means limiting the freedom and choices of individuals"). For all items, subjects indicated agreement or disagreement on a six-point scale.

For this study, we used short-form versions of Hierarchy and Individualism, each of which consisted of six items (Kahan in press; Kahan, Jenkins-Smith \& Braman 2011). Like the full-form versions, the two six-item sets formed reliable scales (Hierarchy, $\alpha=0.84$; Individualism, $\alpha=0.76$ ), the items of which loaded appropriately on two separate factors, which were labeled "Hierarchy" and "Individualism" and used as predictors for the study. 


\section{Cultural Cognition of Risk}

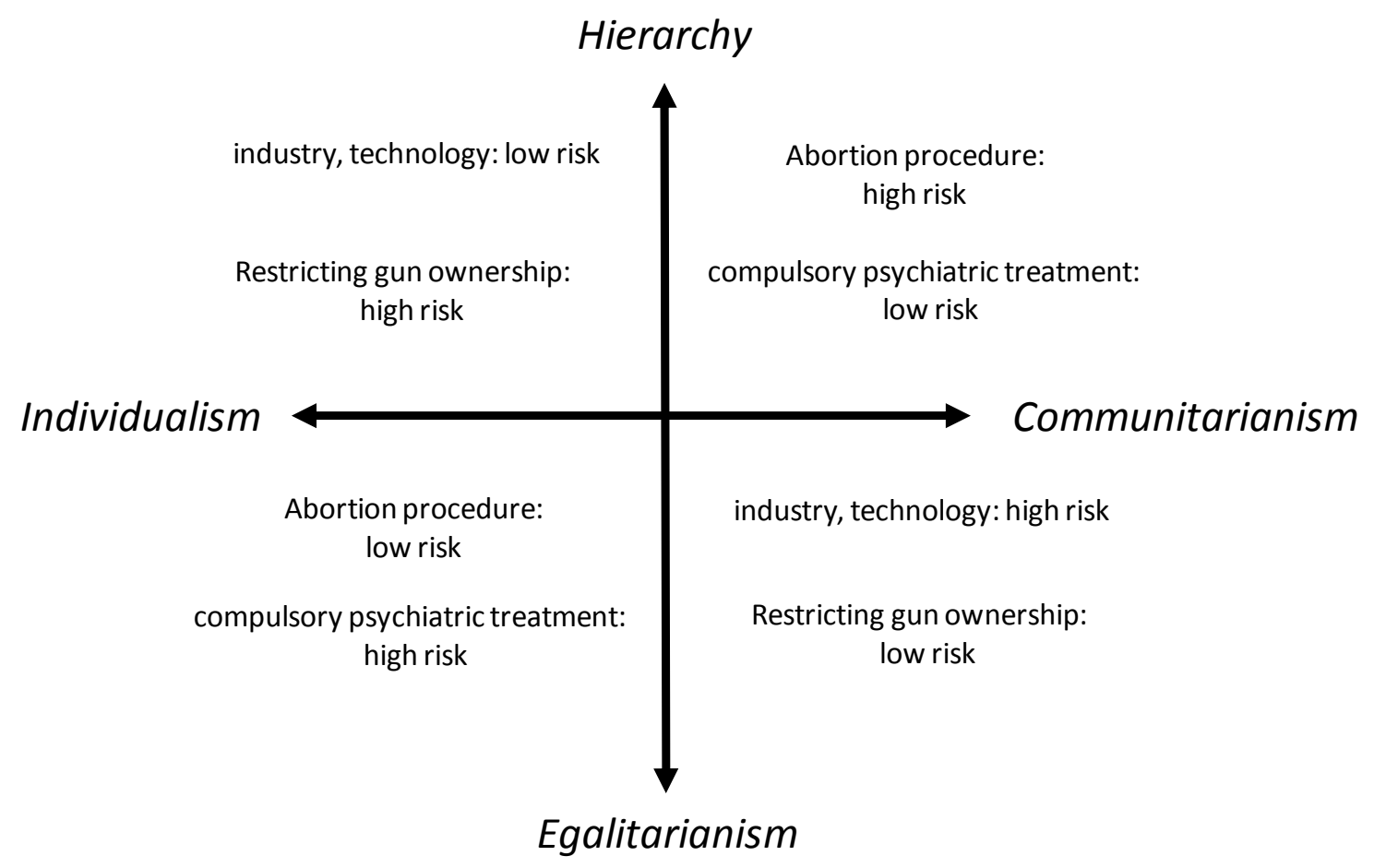

SI Figure 5. Cultural cognition of risk. Using attitudinal scales, the cultural cognition theory measures cultural worldviews, or preferences for how society and other collective undertakings should be organized, along two dimensions, "Hierarchy-Egalitarianism" and "Individualism-Communitarianism." The theory on which it is based predicts that perceptions of environmental and technological risks should be expected to diminish as worldviews become simultaneously more hierarchical and individualistic, and increase as worldviews become simultaneously more egalitarian and communitarian. Other types of risks, including ones relating to public health and social deviance, can be expected to vary more dramatically as worldviews become progressively more hierarchical and communitarian or progressively more egalitarian and individualistic. (Kahan in press; Wildavsky \& Dake, 1990).

b. Numeracy. Subjects' numeracy - their proficiency in understanding quantitative information and engaging in mathematical reasoning - was measured with a set of 14 questions (SI Table 1) used in previous studies (e.g., Peters, Västfjäll, Slovic, Mertz, Mazzocco \& Dickert 2006; Lipkus, Samsa, \& Rimer 2001; Frederick 2005). Item responses formed a reliable scale $(\alpha=0.85)$, which was labeled "Numeracy." 
EVENROLL

PCTTOFREQUENCY1.

FREQUENCYTOPCT1.

COMPFREQUENCY.

COMPPCT.

DOUBLEPCT.

DOUBLEFREQUENCY.

PCTTOFREQUENCY2.

A:

$\mathrm{B}$ :

FREQUENCYTOPCT2.

VIRAL.

BAYESIAN

SHANE1.

SHANE2.
Imagine that we roll a fair, six-sided die 1,000 times. (That would mean

that we roll one die from a pair of dice.) Out of 1,000 rolls, how many times do you think the die would come up as an even number?

In the BIG BUCKS LOTTERY, the chances of winning a $\$ 10.00$ prize are

$1 \%$. What is your best guess about how many people would win a $\$ 10.00$

prize if 1,000 people each buy a single ticket from BIG BUCKS?

In the ACME PUBLISHING SWEEPSTAKES, the chance of winning a car is 1 in 1,000 . What percent of tickets of ACME PUBLISHING SWEEPSTAKES win a car?

Which of the following numbers represents the biggest risk of getting a disease?

Which of the following numbers represents the biggest risk of getting a disease?

If Person A's risk of getting a disease is $1 \%$ in ten years, and Person B's risk is double that of A's, what is B's risk?

If Person A's chance of getting a disease is 1 in 100 in ten years, and person B's risk is double that of A, what is B's risk?

If the chance of getting a disease is $10 \%$, how many people would be expected to get the disease:

Out of $100 ?$

Out of $1000 ?$

If the chance of getting a disease is 20 out of 100 , this would be the same as having a _ $\%$ chance of getting the disease.

The chance of getting a viral infection is .0005 . Out of 10,000 people, about how many of them are expected to get infected?

Suppose you have a close friend who has a lump in her breast and must have a mammogram. Of 100 women like her, 10 of them actually have a malignant tumor and 90 of them do not. Of the 10 women who actually have a tumor, the mammogram indicates correctly that 9 of them have a tumor and indicates incorrectly that 1 of them does not have a tumor. Of the 90 women who do not have a tumor, the mammogram indicates correctly that 81 of them do not have a tumor and indicates incorrectly that 9 of them do have a tumor. The table below summarizes all of this information. Imagine that your friend tests positive (as if she had a tumor), what is the likelihood that she actually has a tumor?

A bat and a ball cost $\$ 1.10$ in total. The bat costs $\$ 1.00$ more than the ball. How much does the ball cost?

In a lake, there is a patch of lilypads. Every day, the patch doubles in size. If it takes 48 days for the patch to cover the entire lake, how long would it take for the patch to cover half of the lake?

SI Table 1. Numeracy measures and responses. $N=1540$. 
Numeracy was weakly associated with cultural outlooks. The correlation between numeracy and Hierarchy was 0.14 , and between Numeracy and Individualism was -0.07 ( $p<.01$, in both cases). For Hierarchical Individualists, the mean score was $8.0(S E M=0.15)$, and for Egalitarian Communitarians 7.5 $(S E M=0.18)$.

c. Science literacy. To measure science literacy, subjects were asked a set of questions drawn from the National Science Foundation "Science and Engineering Indicators" (NSF 2010). The indicators have been widely used over a long period of time and across a large number of societies as an index of public comprehension of basic science ((Allum, Sturgis, Tabourazi \& Brunton-Smith 2008). We included eight NSF Indicator items in the survey (SI Table 2). The mean number of correct responses was 5.9 (SD $=1.86)$. Responses formed a modestly reliable scale $(\alpha=0.62)$, which was labeled Sciliteracy. The correlation between this variable and the worldview measures was slight (with Hierarchy: $r=0.09, p<0.01$; with Individualism: $r=0.03, p<0.34)$. The mean Sciliteracy score was $6.3(S E M=0.09)$ for Hierarchical Individualists, and $6.0(S E M=0.10)$ for Egalitarian Communitarians.

\begin{tabular}{llr} 
items & & $\%$ correct \\
\hline EARTHOT & The center of the Earth is very hot [true/false]. & $86 \%$ \\
HUMANRADIO & All radioactivity is man-made [true/false]. & $84 \%$ \\
LASERS & Lasers work by focusing sound waves [true/false]. & $68 \%$ \\
ELECATOM & Electrons are smaller than atoms [true/false]. & $62 \%$ \\
COPERNICUS1 & Does the Earth go around the Sun, or does the Sun go around the Earth? \\
COPERNICUS2 & How long does it take for the Earth to go around the Sun? [one day, one month, one year] \\
DADGENDER & It is the father's gene that decides whether the baby is a boy or a girl [true/false]. & $72 \%$ \\
ANTIBIOTICS & Antibiotics kill viruses as well as bacteria [true/false]. & $45 \%$ \\
\hline
\end{tabular}

SI Table 2. Science literacy items. $N=1540$.

\section{Multivariate analyses}

We performed two sets of multivariate regression analyses to test the various hypotheses associated with PIT. The outcome variables were GWRISK and NUKERISK. To minimize collinearity, we combined science literacy and numeracy into a composite scale $(\alpha=0.85)$ (Feldman 1985, p. 48), which was labeled "Science/Numeracy." The z-score transformation of Science/Numeracy (z_sci_num) was 
used as a predictor in the regression analyses in order to center the variable at 0 and thereby enhance the interpretability of models with cross-product interaction terms (Jaccard \& Turrisi 2003, pp. 15-16).

\begin{tabular}{lrlrlrl}
\multicolumn{7}{c}{ Climate Change } \\
& 1 & \multicolumn{2}{c}{2} & \\
\hline z_Sci/Num & $\mathbf{- 0 . 0 9}$ & $(-3.35)$ & -0.03 & $(-1.43)$ & -0.04 & $(-1.70)$ \\
Hierarch & & & $-\mathbf{0 . 4 6}$ & $(-21.06)$ & $\mathbf{0 . 4 6}$ & $(-20.41)$ \\
Individ & & & $-\mathbf{0 . 3 0}$ & $(-13.97)$ & $\mathbf{0 . 3 0}$ & $(-13.57)$ \\
hierarch x z_Sci/Num & & & & & $\mathbf{0 . 0 5}$ & $(-2.30)$ \\
individ x z_Sci/Num & & & & -0.02 & $(-1.12)$ \\
constant & 0.00 & $(-0.02)$ & 0.00 & $(0.00)$ & 0.00 & $(0.14)$ \\
\hline$F$ & $(1,1538)$ & $\mathbf{1 1 . 2 3}$ & $(3,1536)$ & $\mathbf{2 2 1 . 9 9}$ & $(5,1534)$ & $\mathbf{1 3 4 . 6 2}$ \\
$\Delta F$ & & & $(2,1536)$ & $\mathbf{3 2 0 . 7 3}$ & $(2,1534)$ & $\mathbf{3 . 1 0}$ \\
\hline
\end{tabular}

SI Table 3. Multivariate regression analysis of climate change risk perceptions. $N=1540$. Predictors are unstandardized OLS regression coefficients with t-statistic indicated parenthetically. Outcome variable is standardized (z-score) responses to "How much risk do you believe climate change poses to human health, safety, or prosperity?" Bolded indicates that the coefficient, $F$ statistic, or the change in $F$ statistic is significant at $p<0.05$. Note that because all predictors are centered at 0 , the regression coefficients for the predictor and moderator variables in models that contain cross-product interaction terms indicate the effect of the relevant variable when the other is at its mean value (Jaccard \& Turrisi 2003, pp. 15-16). Missing values for individual cultural worldview items and for GWRISK were replaced using multiple imputation (Rubin 2004; Royston 2004).

Sequential models were used to test the impact of Science/Numeracy, the cultural worldviews, and the interactions of these variables. In the first step, risk perceptions were regressed against Science/Numeracy alone, which predicted less concern for both climate-change and nuclear risk perceptions.

The cultural worldview variables were entered next. Both Hierarchy and Individualism predicted less concern for the two forms of risk perception.

In the final step, variables to test for the interaction between science literacy and numeracy, on the one hand, and the cultural worldview variables, on the other, were added to the analyses. Each riskperception measure displayed a significant negative interaction with one worldview variable: climate change with Hierarchy $(b=-0.05, p<0.05)$ and nuclear power with Individualism $(b=-0.05, p<0.05)$. The sign of the remaining individual worldview predictors was negative in both cases but nonsignificant (climate change, Individualism: $b=-0.02, p=0.27$; nuclear power, Hierarchy: $b=-0.04, p=0.11$ ). 
Nuclear Power

\begin{tabular}{lrlrlrl} 
& \multicolumn{2}{c}{1} & \multicolumn{2}{c}{2} & \multicolumn{2}{c}{3} \\
\hline z_Sci/Num & $\mathbf{- 0 . 3 0}$ & $(-12.06)$ & $-\mathbf{0 . 2 7}$ & $(-11.18)$ & $\mathbf{- 0 . 2 8}$ & $(-11.40)$ \\
hierarch & & & $-\mathbf{0 . 2 4}$ & $(-9.82)$ & $\mathbf{- 0 . 2 3}$ & $(-9.28)$ \\
individ & & & $-\mathbf{0 . 1 2}$ & $(-4.86)$ & $\mathbf{- 0 . 1 1}$ & $(-4.59)$ \\
hierarch x z_Sci/Num & & & & & -0.04 & $(-1.59)$ \\
$\begin{array}{l}\text { individ x z_Sci/Num } \\
\text { constant }\end{array}$ & & & & & $\mathbf{0 . 0 5}$ & $(-2.31)$ \\
\hline$F$ & 0.00 & $(0.03)$ & 0.00 & $(-0.05)$ & 0.00 & $(0.09)$ \\
\hline$F$ & $(1,1538)$ & $\mathbf{1 4 5 . 3 4}$ & $(3,1536)$ & $\mathbf{9 1 . 3 9}$ & $(5,1534)$ & $\mathbf{5 6 . 4 8}$ \\
\hline
\end{tabular}

SI Table 4. Multivariate regression analyses of nuclear power risk perceptions. $N=1540$. Predictors are unstandardized OLS regression coefficients with t-statistic indicated parenthetically. Outcome variable is standardized (z-score) responses to "How much risk do you believe nuclear power poses to human health, safety, or prosperity?" Bolded indicates that the coefficient, F-statistic, or the change in F-statistic is significant at $p<0.05$. Note that because all predictors are centered at 0 , the regression coefficients for the predictor and moderator variables in models that contain cross-product interaction terms indicate the effect of the relevant variable when the other is at its mean value (Jaccard \& Turrisi 2003, pp. 15-16). Missing values for individual cultural worldview items and for NUKERISK were replaced using multiple imputation (Rubin 2004; Royston 2004).

Because the impact of even the nonsignificant predictors can result in a significant impact when aggregated consistent with study hypotheses, the most straightforward means to test the hypotheses is to use the regression model to estimate the impact of relevant combinations of predictors (Cohen, Cohen, West \& Aiken 2003, pp. 162-70). Such estimates, based on Model 3 of the analyses, are reported graphically in SI Figure 6 and SI Figure 7. The results confirm the lack of support for the conclusion that science literacy and numeracy predict increased risk concern for climate-change risk perceptions. They confirm, as well, the finding that the cultural worldview variables predict both sets of risk perceptions independently of science literacy and numeracy (that is, when Science/Numeracy is controlled for by being set to its mean). Finally, they demonstrate that as science literacy and numeracy (as reflected in Science/Numeracy) increase, cultural polarization increases for both climate-change risk perceptions and nuclear-power risk perceptions (SI Figure 7). 
"How much risk do you believe ... poses to human health, safety, or prosperity?"

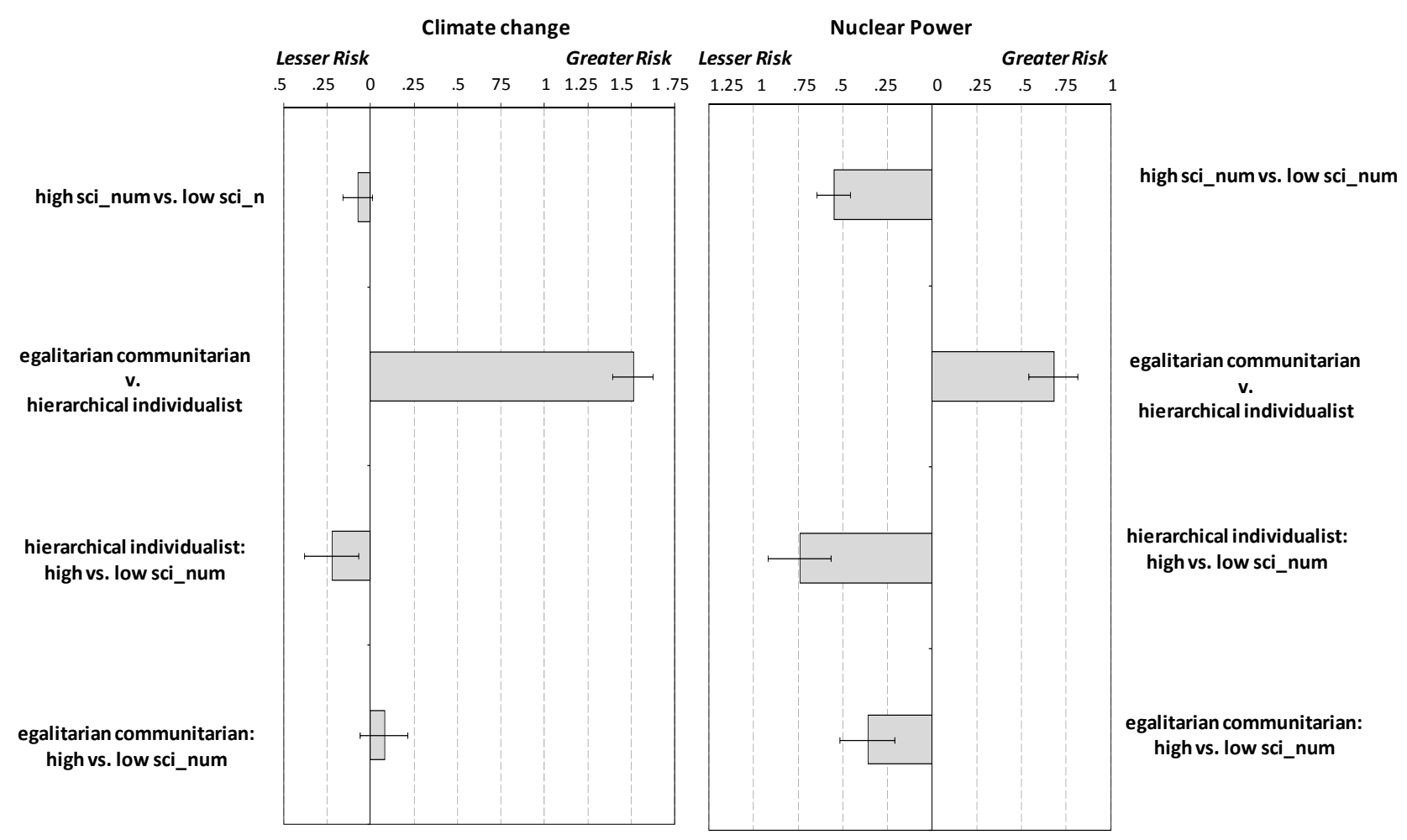

SI Figure 6. Multivariate regression estimates. Estimates derived from Model 3 of the regression outputs reported in SI Table 3 and SI Table 4, respectively. Bars indicate the difference between estimated value of the outcome variable when the indicated predictors are set at the values specified before "versus" and the value of the outcome variable when the indicated predictors are set at the values specified after "versus." For "high" and "low Science/Numeracy," Science/Numeracy predictor values are set at +1 and $-1 S D$, respectively. For "hierarchical individualist" the cultural worldview predictor values are set at $+1 S D$ on both the Hierarchy and Individualism worldview scales, while for "egalitarian communitarian" the predictors are set at $-1 S D$ on both worldview scales. Product-interaction term values are set correspondingly. CIs indicate 0.95 level of confidence. 


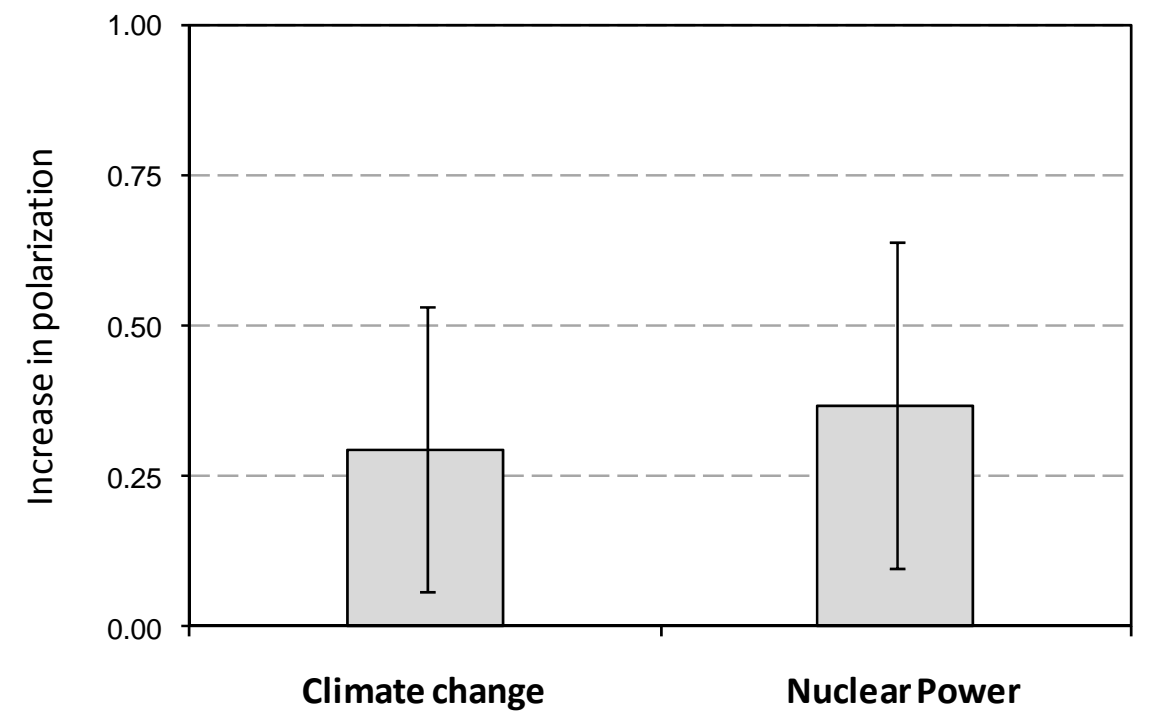

SI Figure 7. Multivariate regression estimates of increased polarization associated with increased numeracy and science literacy. Estimates derived from Model 3 of the regression outputs reported in SI Table 3 and SI Table 4 , respectively. Bars indicate how much larger cultural polarization is when science-literacy and numeracy are high as opposed to low. The estimates are derived by comparing how much larger the difference in the values of outcome variable is between "hierarchical individualist" $(+1 S D$ on both worldview scales) and "egalitarian communitarian" $(-1 S D$ on both scales) when (1) the predictor value for Science/Numeracy is set at a "high" value $(+1 S D)$ than it is when (2) the predictor value for Science/Numeracy is set at a "low" value (-1 $S D)$, with product-interaction term values being correspondingly. CIs indicate 0.95 level of confidence. 


\section{References}

Allum, N., Sturgis, P., Tabourazi, D., \& Brunton-Smith, I. (2008). Science knowledge and attitudes across cultures: a meta-analysis. Public Understanding of Science, 17(1), 35-54.

Anderson, E. (1993). Value in ethics and economics. Cambridge, Mass.: Harvard University Press.

Berry, W. D., \& Feldman, S. (1985). Multiple regression in practice. Beverly Hills: Sage Publications.

Benn, S. (1979). The problematic rationality of political participation. In P. Laslett \& J. S. Fishkin (Eds.), Philosophy, politics, and society, fifth series : a collection (pp. 312-34). Oxford: B. Blackwell.

Chen, S., Duckworth, K., \& Chaiken, S. (1999). Motivated Heuristic and Systematic Processing. Psychological Inquiry, 10(1), 44-49.

Cohen, G. L. (2003). Party over Policy: The Dominating Impact of Group Influence on Political Beliefs. J. Personality \& Soc. Psych., 85(5), 808-822.

Cohen, J., Cohen, P., West, S. G., \& Aiken, L. S. (2003). Applied Multiple Regression/Correlation Analysis for the Behavioral Sciences (3rd ed.). Mahwah, N.J.: L. Erlbaum Associates.

Douglas, M., \& Wildavsky, A. B. (1982). Risk and culture: An essay on the selection of technical and environmental dangers. Berkeley: University of California Press.

Downs, A. (1957). An economic theory of democracy. New York,: Harper.

Druckman J., \& Bolsen T. (In press). Framing, Motivated Reasoning, and Opinions About Emergent Technologies. J. Communication.

Fischhoff, B., Gonzalez, R. M., Small, D. A., \& Lerner, J. S. (2003). Judged Terror Risk and Proximity to the World Trade Center. Journal of Risk and Uncertainty, 26(2), 137-151.

Frederick, S. (2005). Cognitive Reflection and Decision Making. J. Econ. Perspectives, 19(4), 25-42.

Gigerenzer, G. (2000). Adaptive thinking: rationality in the real world. New York: Oxford University Press.

Giner-Sorolla, R., \& Chaiken, S. (1997). Selective Use of Heuristic and Systematic Processing Under Defense Motivation. Personality and Social Psychology Bulletin, 23(1), 84-97.

Hardin, G. (1968). The Tragedy of the Commons. Science, 162(3859), 1243-1248.

Harris, K. M., J. Maurer, and A.L. Kellermann. (2010). Influenza vaccine-safe, effective, and mistrusted. New England Journal of Medicine, 363, 2183-2185.

Hartley, L. M., Wilke, B. J., Schramm, J. W., D'Avanzo, C., \& Anderson, C. W. (2011). College Students' Understanding of the Carbon Cycle: Contrasting Principle-Based and Informal Reasoning. [doi: 10.1525/bio.2011.61.1.12]. BioScience, 61(1), 65-75.

Jaccard, J., \& Turrisi, R. (2003). Interaction Effects in Multiple Regression (2nd ed.). Thousand Oaks, Calif.: Sage Publications. 
Jones, M. D., \& McBeth, M. K. (2010). A Narrative Policy Framework: Clear Enough to Be Wrong? Policy Studies Journal, 38(2), 329-353.

Leiserowitz, A. (2006). Climate change risk perception and policy preferences: The role of affect, imagery, and values. Climatic Change, 77(1-2), 45-72.

Kahan, D. (in press). Cultural Cognition as a Conception of the Cultural Theory of Risk. In Handbook of Risk Theory, Sabine Roeser (Ed.).

Kahan, D. (2010). Fixing the Communications Failure. Nature, 463, 296-297.

Kahan, D. M., Braman, D., Cohen, G. L., Gastil, J., \& Slovic, P. (2010). Who Fears the HPV Vaccine, Who Doesn't, and Why? An Experimental Study of the Mechanisms of Cultural Cognition. L. \& Human Behavior, 34, 501-516.

Kahan, D. M., Braman, D., Gastil, J., Slovic, P., \& Mertz, C. K. (2007). Culture and Identity-Protective Cognition: Explaining the White-Male Effect in Risk Perception. Journal of Empirical Legal Studies, 4(3), 465-505.

Kahan, D. M., Braman, D., Slovic, P., Gastil, J., \& Cohen, G. (2009). Cultural Cognition of the Risks and Benefits of Nanotechnology. Nature Nanotechnology, 4(2), 87-91.

Kahan, D. M., Jenkins-Smith, H., \& Braman, D. (2011). Cultural Cognition of Scientific Consensus. Journal of Risk Research, 14, 147-174.

Kahneman, D. (2003). Maps of Bounded Rationality: Psychology for Behavioral Economics. American Economic Review, 93(5), 1449-1475.

Kunda, Z. (1990). The Case for Motivated Reasoning. Psychological Bulletin, 108, 480-498.

Lessig, L. (1995). The Regulation of Social Meaning. U. Chi. L. Rev., 62, 943-1045.

McMahon, C. (2001). Collective rationality and collective reasoning. Cambridge, U.K.: Cambridge University Press.

Miller, J. D., Scott, E. C., \& Okamoto, S. (2006). Science communication: public acceptance of evolution. Science, 313(5788), 765-766.

National Science Board. (2010). Science and Engineering Indicators, 2010. Arlington, Va.: National Science Foundation.

Nisbet, M. C., \& Mooney, C. (2007). Framing Science. Science, 316(5821), 56.

Olson, M. (1965). The logic of collective action; public goods and the theory of groups. Cambridge, Mass.: Harvard University Press.

Peters, E., Västfjäll, D., Slovic, P., Mertz, C. K., Mazzocco, K., \& Dickert, S. (2006). Numeracy and Decision Making. Psychological Science, 17(5), 407-413.

Pew Research Center for the People \& the Press. (2009). Public praises science; scientists fault public, media. Washington D.C.: Pew Research Center. 
Pidgeon, N., \& Fischhoff, B. (2011). The role of social and decision sciences in communicating uncertain climate risks. [10.1038/nclimate1080]. Nature Clim. Change, 1(1), 35-41.

Reyna, V. F., Nelson, W. L., Han, P. K., \& Dieckmann, N. F. (2009). How numeracy influences risk comprehension and medical decision making. Pscyh. Bulletin, 135, 943-973.

Royston, P. (2004). Multiple imputation of missing values. Stata Journal, 4(3), 227-241.

Rubin, D. B. (2004). Multiple imputation for nonresponse in surveys. Hoboken, N.J.: Wiley-Interscience.

Sherman, D. K., Cohen, G. L. (2006). The Psychology of Self-defense: Self-Affirmation Theory Advances in Experimental Social Psychology (Vol. 38, pp. 183-242): Academic Press.

Sherman, D. K., \& Cohen, G. L. (2002). Accepting threatening information: Self-affirmation and the reduction of defensive biases. Current Directions in Psychological Science, 11(4), 119-123.

Sunstein, C. R. (2006). Misfearing: A reply. Harvard Law Review, 119(4), 1110-1125.

Sunstein, C. R. (2007). On the Divergent American Reactions to Terrorism and Climate Change. Columbia Law Review, 107, 503-557.

Ungar, S. (2000). Knowledge, ignorance and the popular culture: climate change versus the ozone hole. Public Understanding of Science, 9(3), 297-312.

Verweij, M., Douglas, M., Ellis, R., Engle, C., Hendriks, F., Lohmann, S., Ney, S., Rayner, S. \& Thompson, M. Clumsy Solutions for a Complex World: The Case of Climate Change. Public Administration 84, 817-843 (2006).

Weber, E. (2006). Experience-Based and Description-Based Perceptions of Long-Term Risk: Why Global Warming does not Scare us (Yet). Climatic Change, 77(1), 103-120.

Weber, E. U., \& Stern, P. C. (2011). Public Understanding of Climate Change in the United States. Am. Psychologist, 66, 315-328.

Wildavsky, A., \& Dake, K. (1990). Theories of risk perception: Who fears what and why? Daedalus, 114, 41-60. 